\title{
Incidence and Predictors of Pregnancy among a Cohort of HIV-Positive Women Initiating Antiretroviral Therapy in Mbarara, Uganda
}

\author{
Angela Kaida ${ }^{1 *}$, Lynn T. Matthews ${ }^{2,3,4}$, Steve Kanters ${ }^{5}$, Jerome Kabakyenga ${ }^{6}$, Conrad Muzoora ${ }^{6}$, A. \\ Rain Mocello7, Jeffrey N. Martin ${ }^{7}$, Peter Hunt ${ }^{7}$, Jessica Haberer ${ }^{3,4}$, Robert S. Hogg ${ }^{1,8}$, \\ David R. Bangsberg ${ }^{3,4,6}$
}

1 Simon Fraser University, Burnaby, Canada, 2 Beth Israel Deaconess Medical Center, Boston, Massachusetts, United States of America, 3 Harvard Medical School, Boston, Massachusetts, United States of America, 4 Massachusetts General Hospital, Boston, Massachusetts, United States of America, 5 University of British Columbia, Vancouver, Canada, $\mathbf{6}$ Mbarara University of Science and Technology, Mbarara, Uganda, 7 University of California San Francisco (UCSF), San Francisco, California, United States of America, 8 BC Centre for Excellence in HIV/AIDS, Vancouver, Canada

\begin{abstract}
Objective: Many people living with HIV in sub-Saharan Africa desire biological children. Implementation of HIV prevention strategies that support the reproductive goals of people living with HIV while minimizing HIV transmission risk to sexual partners and future children requires a comprehensive understanding of pregnancy in this population. We analyzed prospective cohort data to determine pregnancy incidence and predictors among HIV-positive women initiating antiretroviral therapy (ART) in a setting with high HIV prevalence and fertility.

Methods: Participants were enrolled in the Uganda AIDS Rural Treatment Outcomes (UARTO) cohort of HIV-positive individuals initiating ART in Mbarara. Bloodwork (including CD4 cells $/ \mathrm{mm}^{3}$, HIV viral load) and questionnaires (including socio-demographics, health status, sexual behavior, partner dynamics, HIV history, and self-reported pregnancy) were completed at baseline and quarterly. Our analysis includes 351 HIV-positive women (18-49 years) who enrolled between 2005-2011. We measured pregnancy incidence by proximal and distal time relative to ART initiation and used multivariable Cox proportional hazards regression analysis (with repeated events) to identify baseline and time-dependent predictors of pregnancy post-ART initiation.

Results: At baseline (pre-ART initiation), median age was 33 years [IQR: 27-37] and median prior livebirths was four [IQR: 26]. $38 \%$ were married with $61 \%$ reporting HIV-positive spouses. $73 \%$ of women had disclosed HIV status to a primary sexual partner. Median baseline CD4 was 137 cells $/ \mathrm{mm}^{3}$ [IQR: 81-207]. At enrolment, 9.1\% (31/342) reported current pregnancy. After ART initiation, 84 women experienced 105 pregnancies over 3.8 median years of follow-up, yielding a pregnancy incidence of 9.40 per 100 WYs. Three years post-ART initiation, cumulative probability of at least one pregnancy was $28 \%$ and independently associated with younger age (Adjusted Hazard Ratio (AHR): 0.89/year increase; $95 \% \mathrm{Cl}$ : 0.86-0.92) and HIV serostatus disclosure to primary sexual partner (AHR: $2.45 ; 95 \% \mathrm{Cl}: 1.29-4.63$ ).

Conclusions: Nearly one-third of women became pregnant within three years of initiating ART, highlighting the need for integrated services to prevent unintended pregnancies and reduce periconception-related risks for HIV-infected women choosing to conceive. Association with younger age and disclosure suggests a role for early and couples-based safer conception counselling.
\end{abstract}

Citation: Kaida A, Matthews LT, Kanters S, Kabakyenga J, Muzoora C, et al. (2013) Incidence and Predictors of Pregnancy among a Cohort of HIV-Positive Women Initiating Antiretroviral Therapy in Mbarara, Uganda. PLoS ONE 8(5): e63411. doi:10.1371/journal.pone.0063411

Editor: Susan Marie Graham, University of Washington, United States of America

Received May 8, 2012; Accepted April 4, 2013; Published May 21, 2013

Copyright: (C) 2013 Kaida et al. This is an open-access article distributed under the terms of the Creative Commons Attribution License, which permits unrestricted use, distribution, and reproduction in any medium, provided the original author and source are credited.

Funding: Funding for this study was provided by grants from the National Institute of Child Health and Human Development (NICHD R21-HD069194), the National Institute of Mental Health (NIMH R01-MH54907), and the Sullivan Family Foundation. LTM received support from K-23 MH095655 and DRB received support from K-24 MH87227. The funders had no role in study design, data collection and analysis, decision to publish, or preparation of the manuscript.

Competing Interests: The authors have declared that no competing interests exist.

*E-mail: kangela@sfu.ca

\section{Introduction}

In sub-Saharan Africa, the majority of new HIV infections occur in women of reproductive age [1]. Studies in North America $[2,3]$, Europe $[4,5,6]$, and sub-Saharan Africa $[7,8,9,10,11,12,13,14,15]$ consistently report that HIV-infected women and men desire children. HIV-uninfected individuals who seek to conceive with an HIV-infected partner risk acquiring HIV. If conception does occur, pregnancy itself is associated with increased risks of HIV acquisition and transmission [16,17,18].

HIV-infected women and men who desire biological children require strategies to protect at-risk partners and future children from infection $[13,19,20]$. Antiretroviral treatment for the infected partner [21], topical or systemic pre-exposure prophylaxis for the 
uninfected partner $[22,23,24,25]$, and sex without condoms limited to peak fertility offer effective safer conception strategies. In addition, sperm processing and insemination for male-infected couples [26,27], and home insemination [28] and/or male circumcision [29,30,31] for female-infected couples reduce sexual transmission risk for $\mathrm{HIV}$-serodiscordant couples [32,33]. When HIV-positive individuals do not desire children, effective contraception is crucial to prevent unintended and/or unwanted pregnancies $[34,35,36]$.

Successful translation of HIV-prevention strategies that acknowledge the reproductive goals and rights of people living with HIV $[37,38,39,40]$ requires a comprehensive understanding of pregnancy incidence and predictors among HIV-infected and atrisk women. These data are critical to estimate size, characteristics, and needs of priority target populations to support safer conception and contraception, maternal and child health, and HIV treatment and care programs $[10,41,42]$.

Uganda is an important setting in which to investigate pregnancy incidence given high fertility rates (total fertility rate $=6.7$ births per women [43]), endemic HIV (adult HIV prevalence $=6.7 \%$ [1]), and expanding antiretroviral therapy coverage ( $47 \%$ of people eligible for treatment [44]).

The primary objective of this prospective study was to estimate pregnancy incidence and assess baseline and time-updated predictors of pregnancy among reproductive-aged women enrolled in a cohort of HIV-positive individuals initiating ART in a rural region of Uganda.

\section{Methods}

\section{Study Setting}

Mbarara is a rural setting (population 83,700) located approximately 265 kilometres southwest of Kampala. Adult HIV prevalence in the region is estimated at 10\% [45]. The Mbarara University HIV clinic, called the Immune Suppression Syndrome (ISS) clinic, is situated within the Mbarara Regional Referral Hospital. The clinic has served more than 18,000 patients since it opened in 1998 and offers comprehensive HIV care services, including ART, at no cost to patients. ART is provided through the Ugandan Ministry of Health with support from the President's Emergency Plan for AIDS Relief(PEPFAR), the Global Fund, and the Family Treatment Fund [46].

\section{Study Participants}

Study participants were enrolled in the Uganda AIDS Rural Treatment Outcomes (UARTO) cohort study, which was initiated in July 2005 with the primary objective of determining predictors of virologic failure and antiretroviral resistance. Participants were recruited from treatment-naïve patients initiating ART at the HIV clinic. Clinic patients who were at least 18 years old and living within 60 kilometers of the clinic were eligible to enroll in the study. At the time of this analysis, 500 individuals were enrolled in UARTO and $94 \%$ initiated ART within four days of enrolment. The loss-to-follow-up rate (participants for whom we were unable to confirm vital status after $>=180$ days without cohort follow-up) among UARTO participants was $2 \%$ at one year and $5 \%$ at two years. For this analysis of pregnancy incidence, the sample was restricted to female UARTO participants aged 18-49 years.

Over the cohort follow-up period, national antiretroviral treatment guidelines were updated twice. Current (2009) guidelines recommend treatment for HIV-infected adults with GD4 cell count below 250 cells $/ \mathrm{mm}^{3}$, or below 350 cells $/ \mathrm{mm}^{3}$ for those with tuberculosis, pregnancy, or WHO stage III or IV disease [47]. Guidelines for participants who initiated treatment prior to
2009 recommended ART initiation at $\mathrm{CD} 4<200$ cells $/ \mathrm{mm}^{3}$ or WHO Stage IV disease [48,49].

\section{Data Collection}

UARTO participants completed a baseline interview and phlebotomy. They were subsequently scheduled for quarterly follow-up interviews and phlebotomy, concurrent with their scheduled clinic visits. Standardized interviewer-administered questionnaires detailed demographics, mental and physical health, sexual risk behaviour, and partner dynamics including partner testing and HIV status. Incident pregnancies (and pregnancy outcomes) were assessed quarterly via female participants' selfreport. Interviews took 35-50 minutes to complete and were conducted by trained interviewers fluent in English and Runyankole, the dominant local language.

This analysis includes data from participants enrolled from June 2005 and followed-up through December 2011.

\section{Measures}

The primary outcome was self-reported pregnancy at baseline and over the follow-up period (i.e., post ART-initiation), including both first and recurrent pregnancies. Incidence was computed using standard person-time methods. We applied the following rules to calculate woman-years 'at risk' for pregnancy: (1) Among women who reported pregnancy at baseline, time at risk commenced upon the first subsequent visit where they reported no longer being pregnant; (2) Women who became pregnant during follow-up were censored upon their first visit reporting the pregnancy and uncensored upon their first visit reporting no longer being pregnant; (3) Women who did not become pregnant were censored at the end of the follow-up period; and (4) Women who reported sterilization (tubal ligation or hysterectomy) were censored at baseline or, if during follow-up, upon reported date of the procedure.

We examined the association of incident pregnancy subsequent to ART initiation with baseline and time-updated variables, identified as covariates of pregnancy incidence in previous studies $[8,10,42,50,51,52,53,54,55]$. Baseline variables included sociodemographic characteristics (including age, education, employment, household income, and marital status), reproductive history (including parity), and clinical history (including time since HIV diagnosis, time on ART, AIDS defining illnesses, CD4 cell count at enrolment, and body mass index (BMI)). Time-updated variables were measured quarterly and included CD4 cell count, HIV viral load $<400$ copies/mL, depression (measured using a modified version of the Hopkins Symptom Check List and a cutoff of $\geq 1.75$ as indicative of clinical depression) [56,57,58], the Medical Outcomes Study HIV Health Survey (MOS-HIV) Physical Health and Mental Health Summary scores (scored on a $0-100$ scale, where a higher score indicates better health) $[59,60]$, sexual activity in the previous three months, and disclosure of HIV status to primary sexual partner. 'Disclosure to primary sexual partner' was included as a time-updated variable, which combined information on currently having a primary sexual partner (including spouse or regular partner) and disclosure of HIV status to that partner. This yielded a three-level variable including, (i) having disclosed HIV serostatus to a primary sexual partner; (ii) not having disclosed to a primary sexual partner; or (iii) not having a primary sexual partner (disclosure not applicable). In longitudinal analyses, HIV serostatus disclosure was time-updated based on changes in relationship status.

We also report pregnancy outcomes, based on participant selfreport. The outcome categories include live birth or "stillbirth/ miscarriage/termination" - the latter category includes three 
Table 1. Baseline characteristics of female UARTO participants aged 18-49 years by pregnancy after ART initiation'.

\begin{tabular}{|c|c|c|c|c|}
\hline & $\begin{array}{l}\text { Overall }(n=351) \\
n(\%) \text { or median } \\
\text { (IQR) }\end{array}$ & $\begin{array}{l}\text { Pregnancy after ART } \\
\text { initiation } \\
(n=84) \\
n(\%) \text { or median (IQR) }\end{array}$ & $\begin{array}{l}\text { No pregnancy after ART } \\
\text { initiation } \\
(n=230) \\
n(\%) \text { or median (IQR) }\end{array}$ & p-value \\
\hline Median follow-up (years) & $3.8(2.4-4.6)$ & $4.1(2.7-4.7)$ & $4.0(2.7-4.7)$ & 0.891 \\
\hline \multicolumn{5}{|l|}{ Socio-demographic characteristics } \\
\hline Median Age (years) & $33(27-37)$ & $28(24-33)$ & $35(30-39)$ & $<0.001$ \\
\hline Employed & $240(68 \%)$ & $47(56 \%)$ & $165(72 \%)$ & 0.020 \\
\hline Education: Post- primary school & $82(23 \%)$ & $16(19 \%)$ & $58(25 \%)$ & 0.623 \\
\hline $\begin{array}{l}\text { Median monthly household income } \\
(\text { UGX) }\end{array}$ & $30,000(10,000-60,000)$ & $30,000(10,000-54,000)$ & $30,000(10,000-80,000)$ & 0.859 \\
\hline \multicolumn{5}{|l|}{ Marital Status } \\
\hline Married $^{3}$ & $133(38 \%)$ & 45 (54\%) & $69(30 \%)$ & $<0.001$ \\
\hline Never married & $26(7 \%)$ & $10(12 \%)$ & $15(7 \%)$ & \\
\hline Widowed & $89(26 \%)$ & $9(11 \%)$ & $74(32 \%)$ & \\
\hline Divorced & $101(29 \%)$ & $20(24 \%)$ & $70(31 \%)$ & \\
\hline Median \# livebirths & $4(2-6)$ & $4(2-5)$ & $4(3-6)$ & 0.088 \\
\hline \multicolumn{5}{|l|}{ Clinical status characteristics } \\
\hline $\begin{array}{l}\text { Median time between HIV diagnosis } \\
\text { and ART initiation (months) }\end{array}$ & $14(4-36)$ & $13(5-25)$ & $15(4-39)$ & 0.245 \\
\hline Ever had AIDS Defining IIIness & $174(50 \%)$ & $42(50 \%)$ & $115(50 \%)$ & 0.797 \\
\hline BMI $\left(\mathrm{kg} / \mathrm{m}^{2}\right)$ & & & & 0.567 \\
\hline$<18.5$ & $42(12 \%)$ & $10(12 \%)$ & $24(10 \%)$ & \\
\hline$[18.5-25)$ & $238(70 \%)$ & $62(74 \%)$ & $163(70 \%)$ & \\
\hline 25 or more & $59(17 \%)$ & $12(14 \%)$ & $43(18 \%)$ & \\
\hline Median BMI $\left(\mathrm{kg} / \mathrm{m}^{2}\right)$ & $21(20-24)$ & $22(20-24)$ & $21(20-25)$ & 0.787 \\
\hline Depression $^{4}$ & 127 (36\%) & $32(38 \%)$ & $84(37 \%)$ & 0.793 \\
\hline Median CD4 cells $/ \mathrm{mm}^{3}$ & $137(81-207)$ & $154(88-230)$ & $137(87-199)$ & 0.219 \\
\hline Virally suppressed (<400 copies/mL) & $15(4 \%)$ & $2(2 \%)$ & $1(<1 \%)$ & 0.770 \\
\hline $\begin{array}{l}\text { MOS-HIV Mental Health Summary } \\
\text { score }\end{array}$ & $52(44-57)$ & $52(41-57)$ & $51(45-56)$ & 0.790 \\
\hline $\begin{array}{l}\text { MOS-HIV Physical Health Summary } \\
\text { score }\end{array}$ & $53(44-59)$ & $55(46-59)$ & $53(43-58)$ & 0.080 \\
\hline \multicolumn{5}{|l|}{ Sexual behaviour characteristics } \\
\hline Sex in the past 3 months & $155(44 \%)$ & $55(65 \%)$ & $82(36 \%)$ & $<0.001$ \\
\hline \# of sexual partners in past 3 months ${ }^{5}$ & & & & 0.242 \\
\hline 1 & $148(95 \%)$ & $54(98 \%)$ & $76(93 \%)$ & \\
\hline $2+$ & $7(5 \%)$ & $1(2 \%)$ & $6(7 \%)$ & \\
\hline Spouse HIV-positive $^{6}$ & $81(61 \%)$ & $29(64 \%)$ & 39 (57\%) & 0.280 \\
\hline Spouse on $\mathrm{ART}^{7}$ & $39(48 \%)$ & $10(34 \%)$ & $22(56 \%)$ & 0.090 \\
\hline $\begin{array}{l}\text { HIV serostatus disclosed to primary } \\
\text { partner }^{8}\end{array}$ & 111 (73\%) & 46 (84\%) & $51(65 \%)$ & 0.015 \\
\hline
\end{tabular}

'351 women had enrolment information and are counted in the 'Overall' column. 314 had one or more follow-up visits (i.e., 37 women are excluded from the following two columns assessing pregnancy post ART initiation).

${ }^{2}$ UGX is the currency symbol for Ugandan Shillings. 30,000 UGX $\sim \$ 12.20$ USD (conversion rate: 1 USD $=2,458$ UGX)

${ }^{3}$ Married or living as married, as per self-report.

${ }^{4}$ Depression was screened using the Hopkins Symptom Check List modified for use among people living with HIV with a cut-off of $\geq 1.75$ indicating depression

${ }^{5}$ Restricted to $n=155$ who reported sex in the past 3 months (55 among those with pregnancy and 82 among those without pregnancy.).

${ }^{6}$ Restricted to $n=133$ who reported being currently married ( 45 among those with pregnancy, 69 among those without pregnancy.).

${ }^{7}$ Restricted to $n=81$ women with an HIV-positive spouse ( 29 among those with pregnancy, 39 among those without pregnancy.).

${ }^{8}$ Restricted to $\mathrm{n}=151$ who reported having a spouse or regular sexual partner (55 among those with pregnancy, 79 among those without pregnancy.).

doi:10.1371/journal.pone.0063411.t001

possible outcomes asked as one composite outcome measure in the interviews.

\section{Statistical Analyses}

Baseline characteristics of women with and without pregnancies subsequent to ART initiation were compared using Wilcoxon rank 
sum test for continuous variables and Fisher's exact test for categorical variables.

We computed baseline pregnancy prevalence (all pregnancies reported at or within 12 months prior to cohort enrolment), cumulative incidence of pregnancy, and pregnancy outcome post ART-initiation. Pregnancy incidence was calculated using persontime methods and is reported as number of pregnancies per 100 woman-years (WYs) of follow-up. Time between cohort enrolment to pregnancy or end of follow-up period was calculated for each participant. We present data on overall pregnancy incidence as well as pregnancy incidence (overall and first pregnancy) within specified time intervals to distinguish between proximate and distal associations between ART initiation and pregnancy incidence.

Kaplan-Meier curves display trends in pregnancy incidence over time stratified by key baseline characteristics, including age, marital status, and HIV serostatus disclosure to primary sexual partner. Log-rank and likelihood ratio tests were used to test differences in curves by predictor variable strata.

We modeled repeated events in a survival analysis with timedependent covariates using Cox proportional hazards regression to identify independent predictors of pregnancy subsequent to ART initiation. The modified sandwich estimator was used to account for repeated measures among women with more than one pregnancy during follow-up [61]. Follow-up time began at treatment initiation or at first non-pregnant visit for women who were pregnant at treatment initiation (i.e., baseline). After testing for co-linearity and interactions, variables with significant association with pregnancy in the bivariate analysis were considered for the full model to obtain the relative contribution of each covariate, expressed as an adjusted hazard ratio (AHR) with a 95\% confidence interval. Model selection was achieved by minimizing the Akaike information criterion (AIC) while maintaining p-values for covariates below 0.20 [62]. All statistical tests were 2-sided and were considered significant at $\alpha=0.05$. Data were analyzed with SAS version 9.3 [63].

\section{Ethical Statement}

All participants provided voluntary, written informed consent at study enrolment. All procedures were approved by the Institutional Ethics Review Board of Mbarara University of Science and Technology (MUST), the Uganda National Council on Science and Technology (UNCST), Partners Human Research Committee, and the Research Ethics Board of Simon Fraser University.

\section{Results}

\section{Baseline Characteristics}

351 women aged 18-49 years with baseline data were eligible for this study. Analysis of incident pregnancy and predictors was restricted to 314 women with at least one follow-up visit, who contributed 1117.6 woman-years (WYs) of follow-up with a median follow-up time of 3.8 years (IQR: $2.4-4.6$ ).

Median age was 33 years (IQR: 27-37), 23\% had more than a primary school education, $68 \%$ were employed, and median monthly household income was 30,000 (IQR: 10,000-60,000) Ugandan Shillings ( $\$ 12$ USD). Thirty-eight percent of women were currently married or living as married. Of 133 married women, 61\% reported an HIV-positive spouse, of whom $48 \%$ were on ART. Median number of prior live births was 4 (IQR: 26) (Table 1).

Forty-four percent of women reported sexual activity in the prior three months, of whom $95 \%$ reported only one partner and $5 \%$ reported two or more partners. Among women reporting a spouse and/or regular sexual partner, 73\% had disclosed HIV status to this partner.

Median time between HIV diagnosis and ART initiation was 14 months (IQR: 4-36 months), 50\% reported ever having an AIDSdefining illness, and median body mass index (BMI) was $21 \mathrm{~kg} / \mathrm{m}^{2}$ (IQR: 20-24). Overall median CD4 cell count at enrolment was 137 cells $/ \mathrm{mm}^{3}$ (IQR: 81-207), and, consistent with national guidelines to initiate therapy for pregnant women, was higher among women pregnant at enrolment $\left(226\right.$ cells $/ \mathrm{mm}^{3}$ (IQR: 174 397)) compared with women not pregnant at enrolment (135 cells $/ \mathrm{mm}^{3}$ (IQR: 81-202); $\left.\mathrm{p}<0.0001\right)$. Thirty-six percent of women screened positive for depression at baseline. Median MOS-HIV Physical Health and Mental Health Summary scores were 52 (IQR: 44-57) and 53 (IQR: 44-59), respectively.

\section{Pregnancy Prevalence and Outcomes at Baseline}

Among 342 women with baseline data, 23 (6.7\%) women reported pregnancy within 12 months prior to enrolment and 31 $(9.1 \%)$ reported pregnancy at enrolment. The 31 baseline pregnancies resulted in 24 live births, two terminations/miscarriages/or stillbirths, and four women remained pregnant at censoring ( 1 missing outcome).

Of the 31 women pregnant at ART initiation, 63\% reported HIV diagnosis more than 9 months prior to enrolment. Thus, at least $63 \%$ of the prevalent pregnancies occurred among women who knew their positive HIV status prior to conception.

\section{Incidence of Pregnancy after Initiation of ART}

Among 314 women with at least one follow-up visit, 84 reported pregnancy over the follow-up period. Of these women, 66 reported a single incident pregnancy, 15 reported two incident pregnancies, and three women reported three incident pregnancies, totalling 105 pregnancies over $1117.6 \mathrm{WYs}$ of follow-up (pregnancy incidence $=9.40$ per $100 \mathrm{WYs} ; 95 \%$ CI: $7.68,11.4$ ). The 105 pregnancies resulted in 57 live births (54\%), 22 terminations/miscarriages/or stillbirths (21\%), and 12 women remained pregnant as of their most recent visit (11\%) (14 missing outcomes $(13 \%))$.

As shown in Figure 1, incidence of pregnancy (including first and recurrent pregnancies) was higher with recent initiation of ART. Incidence of first pregnancy peaked between 6-12 months after ART initiation (15.2 pregnancies per 100 WYS (95\% CI: 9.53, 23.0)), declined and stabilized between 12-36 months, then decreased sharply 36 months after ART initiation (Table S1). Recurrent pregnancies peaked between 24-30 months and again at $48+$ months after ART initiation. When first and recurrent pregnancy incidence are combined, overall pregnancy incidence peaked 6-12 months after ART initiation (15.5 pregnancies per 100 WYs (95\% CI: 9.80, 23.2), dipped between 12-18 months, and showed a second peak from 18 through 30 months. After 30 months, we observed a steep decline in pregnancy incidence until $48+$ months, when pregnancy incidence rebounded slightly. As shown in Figure 1, the higher overall incidence of pregnancy at 24-30 months and 48+ months was principally due to recurrent pregnancies.

\section{Probability of Pregnancy Over Time}

By one, two, and three years post-ART initiation the overall probability of pregnancy was $12 \%, 20 \%$, and $28 \%$, respectively

\section{(Figure 2.a).}

When stratifying by key baseline characteristics, for younger women (less than 35 years of age, the peak childbearing years for Ugandan women [43] (Figure 2.b), the probability of pregnancy after ART initiation was $18 \%, 29 \%$, and $42 \%$, by years one, two, 


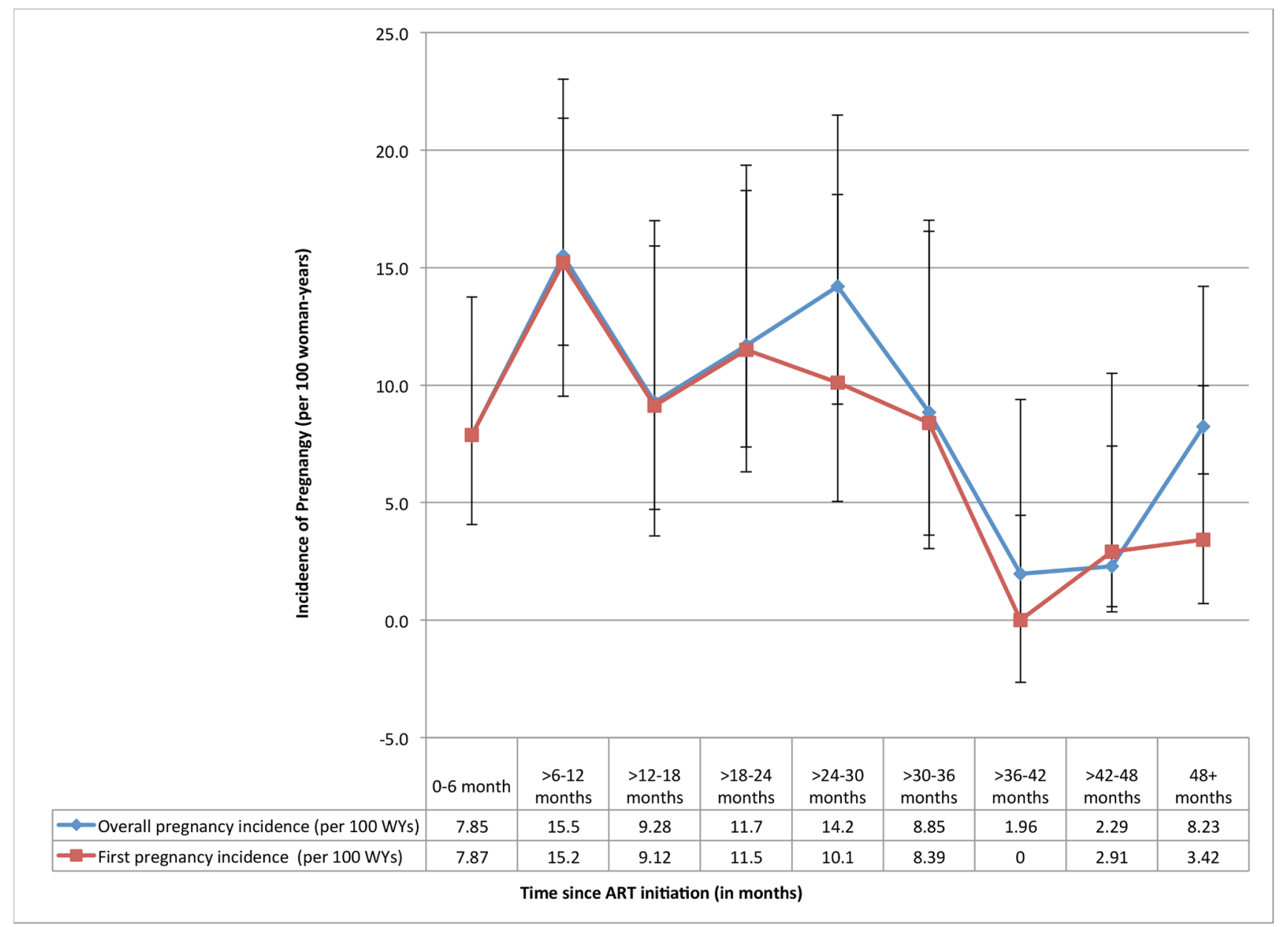

Figure 1. Incidence of overall and first pregnancy. Incidence of overall and first pregnancy (per 100 woman-years) by 6-month intervals post ART initiation (in months) $(n=314)$.

doi:10.1371/journal.pone.0063411.g001

and three respectively. Similarly, among women who were married at baseline (Figure 2.c), the cumulative probability of pregnancy by year three was $43 \%$. Further, among women with a regular sexual partner (spouse or otherwise) to whom they disclosed their HIV status, the cumulative probability of pregnancy by year three was $52 \%$. As further shown in Figure 2.d, disclosure showed a delayed effect on probability of pregnancy as it was only associated with a higher incidence among those pregnancies occurring 12 months after ART initiation.

\section{Baseline and Time-updated Predictors of Pregnancy Post ART-initiation}

In the unadjusted analysis (Table 2), factors associated with an increased risk of pregnancy after ART initiation included younger age (time-updated) (hazard ratio (HR): 0.90 per 1 year increase in age; 95\% CI: 0.87-0.93), being married (HR: 1.93; 95\% CI: $1.31-$ 2.83), having disclosed HIV status to a primary sexual partner (time-updated) (HR: 1.90; 95\% CI: 1.02-3.56), higher CD4 cell count (time-updated) (HR: 1.21 per 100 cells/uL increase; 95\% CI: 1.03-1.40), and HIV diagnosis within 12-30 months of initiating ART (versus >30 months) (HR: 1.97; 95\% CI: 1.14 3.41). Employed women had a lower risk of pregnancy after ART initiation (HR: 0.56; 95\% CI: 0.38-0.83).
In the adjusted model (Table 2), younger age and having disclosed HIV status to primary sexual partner (both timeupdated) remained independently associated with pregnancy risk (adjusted hazard ratio (AHR) $=0.89$ per year increase in age; $95 \%$ CI: $0.86-0.92$ and AHR $=2.45$; 95\% CI: $1.29-4.63$ among those who disclosed compared with those who did not disclose).

As described in the methods, 'Disclosure to a primary partner' combines information regarding currently having/not having a primary sexual partner (including spouse and/or regular partners) and disclosure to that partner. The ' $\mathrm{N} / \mathrm{A}^{\prime}$ ' category denotes that the woman does not currently have a regular sexual partner. In the adjusted model, there was no statistically significant difference in pregnancy risk between those without a primary sexual partner and those with a primary sexual partner to whom they had not disclosed HIV status, suggesting that the explanatory power of this variable stems from the presence or absence of disclosure, beyond the presence or absence of a primary sexual partner.

\section{Discussion}

In this study, we describe the incidence of pregnancy among HIV-infected women initiating ART. Baseline pregnancy prevalence was $9 \%$ and pregnancy incidence was 9.40 per $100 \mathrm{WYs}$ during a median of 3.8 years of follow-up after initiation of ART. By one, two, and three years after ART initiation, the overall 


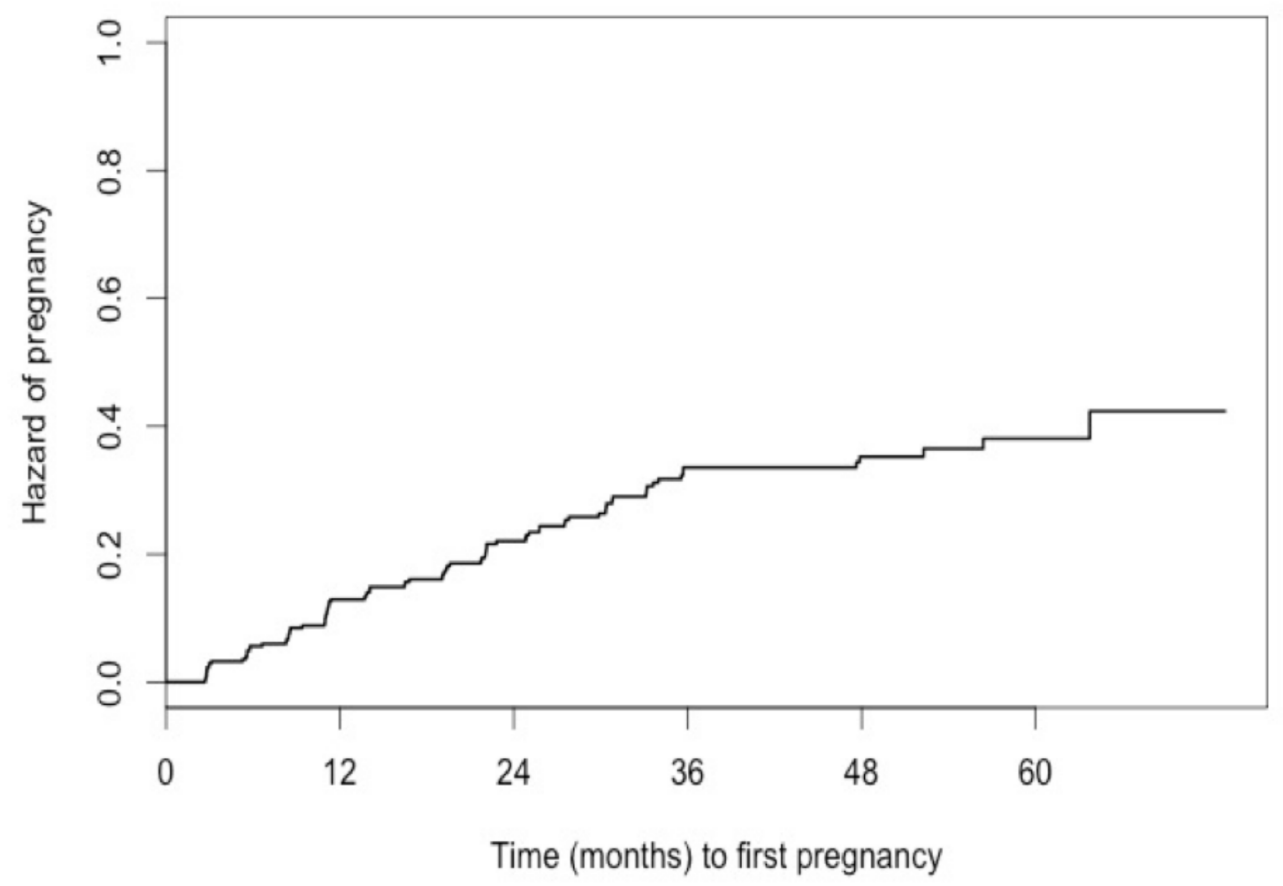

Figure 2. (a-d). Kaplan-Meier curves of probability of pregnancy. Kaplan-Meier curves of probability of pregnancy over time $(n=314)$. Figure 2a. Overall. Figure $2 \mathrm{~b}$. Stratified by age. Figure $2 \mathrm{c}$. Stratified by marital status. Figure $2 \mathrm{~d}$. Stratified by disclosure. Figure $2 \mathrm{a}$. Probability of pregnancy over time among HIV-positive women initiating ART. Figure 2b. Probability of pregnancy over time among HIV-positive women initiating ART, stratified by age ( $<35$ years vs. $>=35$ years). Figure 2c. Probability of pregnancy over time among HIV-positive women initiating ART, stratified by marital status (Currently married vs. not currently married). Figure 2d. Probability of pregnancy over time among HIV-positive women initiating ART, stratified by disclosure of HIV status to primary partner (Non-disclosure vs. Disclosure vs. No primary partner (N/A)). doi:10.1371/journal.pone.0063411.g002

cumulative probability of pregnancy in this cohort was $12 \%, 20 \%$, and $28 \%$, respectively.

Among women reporting pregnancy at baseline, over one-third were diagnosed with HIV during the pregnancy. The remaining two-thirds became pregnant after knowing their HIV status but before ART initiation. For these women, conception and pregnancy were likely associated with increased risks of poor health outcomes and of HIV transmission to sexual partners.

The observed pregnancy incidence of 9.40 pregnancies per 100 WYS is within the range of comparable regional studies of reproductive-aged women initiating ART [10,42,64,65,66]. This incidence is lower than that reported in studies employing inclusion criteria that affect probability of pregnancy, including younger age group [67] and non-use of injectable contraception [41].

We cannot directly assess whether pregnancy incidence among this cohort differs from HIV-infected women not on ART. A retrospective study of pregnancy incidence among women receiving HIV treatment and care at the referral clinic for this cohort reported a similar pregnancy incidence (8.6 pregnancies per $100 \mathrm{WYs}$ ) with no difference by ART use [68]. Other regional studies enrolling HIV-positive ART-naive women have reported similar [53] or higher [69,70,71] pregnancy incidence. A large multi-country study found a lower incidence of subsequent pregnancy among women initiating ART during pregnancy with substantial variability in rates by individual country setting [42]. The recent results of the DART trial, which enrolled women initiating ART in Uganda and Zimbabwe, similarly reported a lower incidence of pregnancy (4.4 per 100 woman years [95\% CI 4.0-4.9] [66].

The pregnancy incidence observed among UARTO participants is lower than for the general Ugandan population. The agespecific fertility rate of women aged $30-34$ years in Uganda is 24.8 births per 100 women [72] which, while not directly comparable, is well above a pregnancy rate of 9.40 pregnancies per $100 \mathrm{WYs}$ found in this study. This is consistent with data that suggest HIVinfected women have lower fertility than HIV-uninfected women $[73,74,75]$.

The pregnancy incidence observed in this and other studies, coupled with estimates from the same site reporting that $85 \%$ of HIV-positive women do not intend to become pregnant $[12,76]$ but have low rates of contraceptive use [77] and regional estimates that most pregnancies among women with HIV are reported as unplanned and/or unwanted [10,78] reinforces the need for improved, comprehensive reproductive counselling that promotes contraception to avoid unwanted pregnancies and safer conception for women who want pregnancy.

We observed that incidence of pregnancy varied with time since ART initiation, with highest incidence in periods proximal to ART initiation (with a peak in pregnancy incidence between 6-12 months) and lower incidence in periods distal to ART initiation. Four years after ART initiation, we observed a resurgence in pregnancy incidence, largely accounted for by recurrent pregnancies. Other regional studies have reported an independent effect of ART on increasing pregnancy incidence over time compared with ART-naïve women $[10,41,42]$. This is consistent with studies from 
Table 2. Cox proportional hazard regression analysis of baseline and time-updated factors associated with pregnancy after ARTinitiation $(n=314)$.

\begin{tabular}{|c|c|c|}
\hline Variable & Unadjusted Hazard Ratio (HR) $(95 \% \mathrm{Cl})$ & Adjusted Hazard Ratio (AHR) $(95 \% \mathrm{Cl})$ \\
\hline \multicolumn{3}{|l|}{ Socio-demographic characteristics } \\
\hline Age (time-updated) & $0.90(0.87-0.93)$ & $0.89(0.86-0.92)$ \\
\hline Employed: Yes vs. No & $0.56(0.38-0.83)$ & - \\
\hline Education: Post-primary school vs. less education & $0.81(0.54-1.20)$ & - \\
\hline Median monthly household income (per 10,000 UGX increase) & $1.01(0.99-1.02)$ & - \\
\hline Marital Status: Married vs. Not married & $1.93(1.31-2.83)$ & $\ddagger$ \\
\hline Number of prior Live Births: & & - \\
\hline $4+v s .<4$ & $0.88(0.60-1.30)$ & \\
\hline $2+$ vs. $0-1$ (as an alternate cut-off) & $0.61(0.37-1.01)$ & \\
\hline \multicolumn{3}{|l|}{ Clinical status characteristics } \\
\hline \multicolumn{3}{|l|}{ Months since HIV diagnosis } \\
\hline$<12$ vs. more than 30 & $1.34(0.80-2.23)$ & - \\
\hline $12-30$ vs. more than 30 & $1.97(1.14-3.41)$ & \\
\hline AIDS-defining Illness (ADI) at baseline & $1.24(0.82-1.88)$ & - \\
\hline BMI at baseline $\left(\mathrm{kg} / \mathrm{m}^{2}\right)$ & $0.99(0.94-1.05)$ & - \\
\hline Depression (time-updated) & $1.14(0.77-1.70)$ & - \\
\hline CD4 cell count (per 100 cells/uL) (time-updated) & $1.21(1.03-1.40)$ & - \\
\hline Viral suppression (time-updated) & $1.70(0.91-3.18)$ & - \\
\hline MOS-HIV Mental Health Summary score (time-updated) & $0.99(0.97-1.01)$ & - \\
\hline MOS-HIV Physical Health Summary score (time-updated) & $1.02(1.00-1.04)$ & - \\
\hline \multicolumn{3}{|l|}{ Sexual behaviour } \\
\hline \multicolumn{3}{|l|}{ Spouse HIV positive at baseline } \\
\hline Yes vs. No & $0.95(0.44-2.03)$ & - \\
\hline N/A vs. No & $0.40(0.18-0.86)$ & \\
\hline DK vs. No & $0.74(0.33-1.65)$ & \\
\hline Spouse on ART at baseline & $0.71(0.37-1.40)$ & - \\
\hline \multicolumn{3}{|l|}{ HIV serostatus disclosed to primary partner (time-updated) ${ }^{\ddagger}$} \\
\hline Yes vs. No & $1.90(1.02-3.56)$ & $2.45(1.29-4.63)$ \\
\hline N/A vs. No & $0.65(0.34-1.24)$ & $0.78(0.41-1.50)$ \\
\hline
\end{tabular}

Notes:

${ }^{\ddagger}$ Disclosure to primary partner' combines information between sex with regular partner (including spouse) and disclosure. The N/A category implies that the individual does not have a regular sexual partner. Given collinearity between 'Disclosure to primary partner' and 'marital status', only 'Disclosure to primary partner' was included in the final adjusted model.

doi:10.1371/journal.pone.0063411.t002

North America and Europe reporting an increase in pregnancy and birth rates among HIV-positive women after widespread availability of ART $[51,54,79,80]$. Whether increased pregnancy incidence after ART is a result of biological (e.g., improved fecundity) or behavioural change (e.g. improved sexual drive with restored health, increased fertility intentions) is not well understood but is likely due to a combination of factors $[10,42,74,81,82]$. These data underscore the need to incorporate comprehensive reproductive counselling for women upon HIV diagnosis and prior to ART initiation, rather than waiting and expecting women to initiate discussions with healthcare providers once they intend to become pregnant $[67,83]$.

Independent, time-varying predictors of incident pregnancy in this cohort include younger age and disclosure of HIV status to a primary sexual partner. Younger age has been associated with higher fertility desire $[7,9,12,14,81,84]$, lower contraceptive use [82], higher fecundity [85], strong societal and partner pressures towards early and frequent childbearing [81], and higher incident pregnancy in several studies of both HIV-positive women $[10,41,42,53]$ [66] and women in general [86].

As shown in Figure 2.b, among women under 35 years of age, the probability of pregnancy within three years of ART initiation was $42 \%$, compared with $11 \%$ probability among women older than 35. While all women of reproductive age are at risk for pregnancy events and should receive routine counselling to discuss reproductive goals and services to prevent unintended pregnancies and reduce periconception-related HIV transmission risks, these data suggests that younger women are a critical target population.

Interviews with pregnant HIV-positive women in Kampala explored the complex role that HIV serostatus disclosure plays in pregnancy decision-making [87]. Disclosure is a precondition for encouraging a partner to engage in HIV risk reduction activities for the purposes of conception or otherwise and has been positively associated with partner HIV testing, increased care seeking, alleviation of anxiety, improved communication, and higher motivation to make plans for the future [88]. Women who 
disclose their status may encounter reduced societal and familial expectations for childbearing [81] but rising community awareness of the benefits of ART may increase pressure to conceive [89].

We observed that serostatus disclosure to the primary sexual partner was a positive and independent predictor of incident pregnancy, however, the effect was not observed until more than one year after ART initiation. Pregnancy intention was not measured in this study, however, the strong association with partner disclosure may suggest that these later pregnancies were wanted and/or planned, or discussed. Those pregnancies occurring in the first year may be highly influenced by the biological and behavioural changes observed with ART initiation and influencing fertility as described above. However, pregnancies occurring more than one-year after ART initiation might be less influenced by those changes and we may be observing a shift to more planned, intended pregnancies. The positive association between serostatus disclosure and pregnancy suggests a role for couples-based safe conception counselling in this population. More research is required to better understand this dynamic relationship.

Spouse HIV-status showed no association with pregnancy. Thirty-nine percent (39\%) of women reported spouses of unknown or negative HIV-status, leaving those men at high risk for periconception or antepartum HIV-acquisition. Male partners play a large role in conception decisions and, if HIV-negative, risk HIV acquisition when seeking to conceive with an HIV-positive partner $[7,13,90]$. Comprehensive reproductive counselling programs must include men.

Limitations of this study include use of self-report for pregnancy, which likely led to an underestimate of the true incidence. Pregnancies resulting in spontaneous abortion prior to detection and pregnancies that were electively terminated may not have been fully captured. Second, we did not have data on fertility intention, pregnancy desire, or contraceptive use, which would have implications for the most appropriate intervention. A higher proportion of unplanned pregnancies would emphasize the need for integrated family planning services including a range of contraceptive options for women initiating ART, who may experience restoration of fecundity. A higher proportion of 'planned' or 'desired' pregnancies would suggest a greater role for periconception risk reduction strategies to minimize HIV

\section{References}

1. UNAIDS (2010) Global Report: UNAIDS Report on the global AIDS epidemic 2010. Geneva: UNAIDS

2. Chen JL, Philips KA, Kanouse DE, Collins RL, Miu A (2001) Fertility desires and intentions of HIV-positive men and women. Fam Plann Perspect 33: 144 152, 165.

3. Ogilvie GS, Palepu A, Remple VP, Maan E, Heath K, et al. (2007) Fertility intentions of women of reproductive age living with HIV in British Columbia, Canada. AIDS 21 (Suppl 1): S83-88.

4. Frodsham LC, Boag F, Barton S, Gilling-Smith C (2006) Human immunodeficiency virus infection and fertility care in the United Kingdom: demand and supply. Fertil Steril 85: 285-289.

5. Heard I, Sitta R, Lert F (2007) Reproductive choice in men and women living with HIV: evidence from a large representative sample of outpatients attending French hospitals (ANRS-EN12-VESPA Study). AIDS 21 (Suppl 1): S77-82.

6. Panozzo L, Battegay M, Friedl A, Vernazza PL (2003) High risk behaviour and fertility desires among heterosexual HIV-positive patients with a serodiscordant partner-two challenging issues. Swiss Med Wkly 133: 124-127.

7. Beyeza-Kashesya J, Ekstrom AM, Kaharuza F, Mirembe F, Neema S, et al. (2010) My partner wants a child: a cross-sectional study of the determinants of the desire for children among mutually disclosed sero-discordant couples receiving care in Uganda. BMC Public Health 10: 247.

8. Brubaker SG, Bukusi EA, Odoyo J, Achando J, Okumu A, et al. (2011) Pregnancy and HIV transmission among HIV-discordant couples in a clinical trial in Kisumu, Kenya. HIV Med 12: 316-321.

9. Cooper D, Moodley J, Zweigenthal V, Bekker LG, Shah I, et al. (2009) Fertility intentions and reproductive health care needs of people living with HIV in Cape Town, South Africa: implications for integrating reproductive health and HIV care services. AIDS Behav 13 (Suppl 1): 38-46. transmission risks. To address these limitations we have initiated a reproductive health study within this cohort to collect these data with the goal of understanding determinants of fertility intention, behaviour, and pregnancy among HIV-affected couples to inform the design of integrated bio-behavioural interventions to mitigate HIV-transmission risk among couples who intend to have children.

\section{Conclusion}

This study measured pregnancy incidence among HIV-positive women initiating ART and followed over a five-year period. Our findings that $9 \%$ were pregnant at ART initiation and that nearly one-third experience pregnancy subsequent to ART initiation highlight the need for integrated reproductive counselling and services that prevent unintended pregnancies and reduce periconception-related risks for HIV-positive women choosing to conceive.

\section{Supporting Information}

Table S1 Incidence of overall and first pregnancy (per 100 woman-years) among HIV-positive women by 6 -month intervals post ART initiation $(\mathrm{n}=314)$.

(DOCX)

\section{Acknowledgments}

The authors would like to thank study participants and our research team for all their contributions to this study.

\section{Author Contributions}

Conceived and designed the experiments: AK LM JK DB. Performed the experiments: AK LM SK ARM. Analyzed the data: AK LM SK ARM. Contributed reagents/materials/analysis tools: AK LM SK ARM JM. Wrote the paper: AK LM. Provided critical review and intellectual contribution to interpretation of study results: AK LM SK JK ARM JM PH CM JH RSH DRB. Provided critical review and intellectual contribution to the first draft of the manuscript: AK LM SK JK ARM JM PH CM JH RSH DRB. Reviewed and approved the final draft of the manuscript: AK LM SK JK ARM JM PH CM JH RSH DRB.
10. Homsy J, Bunnell R, Moore D, King R, Malamba S, et al. (2009) Reproductive intentions and outcomes among women on antiretroviral therapy in rural Uganda: a prospective cohort study. PLoS ONE 4: e4149.

11. Kaida A, Laher F, Strathdee SA, Janssen PA, Money D, et al, (2011) Childbearing intentions of HIV-positive women of reproductive age in Soweto, South Africa: the influence of expanding access to HAART in an HIV hyperendemic setting. Am J Public Health 101: 350-358.

12. Maier M, Andia I, Emenyonu N, Guzman D, Kaida A, et al. (2009) Antiretroviral therapy is associated with increased fertility desire, but not pregnancy or live birth, among HIV+ women in an early HIV treatment program in rural Uganda. AIDS Behav 13 (Suppl 1): 28-37.

13. Matthews LT, Crankshaw T, Giddy J, Kaida A, Smit JA, et al. (2013) Reproductive Decision-Making and Periconception Practices Among HIVPositive Men and Women Attending HIV Services in Durban, South Africa. AIDS Behav 17: 461-470.

14. Myer L, Morroni C, Rebe K (2007) Prevalence and determinants of fertility intentions of HIV-infected women and men receiving antiretroviral therapy in South Africa. AIDS Patient Care STDS 21: 278-285.

15. Nakayiwa S, Abang B, Packel L, Lifshay J, Purcell DW, et al. (2006) Desire for children and pregnancy risk behavior among HIV-infected men and women in Uganda. AIDS Behav 10: S95-104.

16. Kharsany AB, Hancock N, Frohlich JA, Humphries HR, Abdool Karim SS, et al. (2010) Screening for 'window-period' acute HIV infection among pregnant women in rural South Africa. HIV Med 11: 661-665.

17. Moodley D, Esterhuizen TM, Pather T, Chetty V, Ngaleka L (2009) High HIV incidence during pregnancy: compelling reason for repeat HIV testing. AIDS 23: $1255-1259$. 
18. Mugo NR, Heffron R, Donnell D, Wald A, Were EO, et al. (2011) Increased risk of HIV-1 transmission in pregnancy: a prospective study among African HIV-1serodiscordant couples. AIDS 25: 1887-1895.

19. Chadwick RJ, Mantell JE, Moodley J, Harries J, Zweigenthal V, et al. (2011) Safer conception interventions for HIV-affected couples: implications for resource-constrained settings. Top Antivir Med 19: 148-155.

20. Matthews LT, Mukherjee JS (2009) Strategies for harm reduction among HIVaffected couples who want to conceive. AIDS Behav 13 (Suppl 1): 5-11.

21. Cohen MS, Chen YQ, McCauley M, Gamble T, Hosseinipour MC, et al. (2011) Prevention of HIV-1 infection with early antiretroviral therapy. N Engl J Med 365: 493-505.

22. Abdool Karim O, Abdool Karim SS, Frohlich JA, Grobler AC, Baxter C, et al. (2010) Effectiveness and safety of tenofovir gel, an antiretroviral microbicide, for the prevention of HIV infection in women. Science 329: 1168-1174.

23. Baeten JM, Donnell D, Ndase P, Mugo NR, Campbell JD, et al. (2012) Antiretroviral prophylaxis for HIV prevention in heterosexual men and women. N Engl J Med 367: 399-410.

24. Thigpen MC, Kebaabetswe PM, Paxton LA, Smith DK, Rose CE, et al. (2012) Antiretroviral preexposure prophylaxis for heterosexual HIV transmission in Botswana. N Engl J Med 367: 423-434.

25. Van Damme L, Corneli A, Ahmed K, Agot K, Lombaard J, et al. (2012) Preexposure prophylaxis for HIV infection among African women. N Engl J Med 367: 411-422.

26. Bujan L, Hollander L, Coudert M, Gilling-Smith C, Vucetich A, et al. (2007) Safety and efficacy of sperm washing in HIV-1-serodiscordant couples where the male is infected: results from the European CREAThE network. AIDS 21: 1909-1914.

27. Vitorino RL, Grinsztejn BG, de Andrade CA, Hokerberg YH, de Souza CT, et al. (2011) Systematic review of the effectiveness and safety of assisted reproduction techniques in couples serodiscordant for human immunodeficiency virus where the man is positive. Fertil Steril 95: 1684-1690.

28. Mmeje O, Cohen CR, Cohan D (2012) Evaluating safer conception options for HIV-serodiscordant couples (HIV-infected female/HIV-uninfected male): a closer look at vaginal insemination. Infect Dis Obstet Gynecol 2012: 587651.

29. Auvert B, Taljaard D, Lagarde E, Sobngwi-Tambekou J, Sitta R, et al. (2005) Randomized, controlled intervention trial of male circumcision for reduction of HIV infection risk: the ANRS 1265 Trial. PLoS Med 2: e298.

30. Bailey RC, Moses S, Parker CB, Agot K, Maclean I, et al. (2007) Male circumcision for HIV prevention in young men in Kisumu, Kenya: a randomised controlled trial. Lancet 369: 643-656.

31. Gray RH, Kigozi G, Serwadda D, Makumbi F, Watya S, et al. (2007) Male circumcision for HIV prevention in men in Rakai, Uganda: a randomised trial. Lancet 369: 657-666.

32. Bekker L-G, Black V, Myer L, Rees H, Cooper D, et al. (2011) Guideline on safer conception in fertile HIV-infected individuals and couples. Southern African Journal of HIV Medicine 12: 31-44.

33. Matthews LT, Smit JA, Cu-Uvin S, Cohan D (2012) Antiretrovirals and safer conception for HIV-serodiscordant couples. Curr Opin HIV AIDS 7: 569-578.

34. Farrell B (2007) Family planning-integrated HIV services: A framework for integrating family planning and antriretroviral therapy services. New York: EngenderHealth/The ACQUIRE Project.

35. Wilcher R, Cates W, Jr., Gregson S (2009) Family planning and HIV: strange bedfellows no longer. AIDS 23 (Suppl 1): S1-6.

36. World Health Organization (WHO) (2005) Sexual and reproductive health and HIV/AIDS: A framework for priority linkages. Geneva: WHO.

37. Gruskin S, Ferguson L, O'Malley J (2007) Ensuring sexual and reproductive health for people living with HIV: an overview of key human rights, policy and health systems issues. Reprod Health Matters 15: 4-26.

38. Kaida A, Bangsberg DR, Gray G, Hogg RS, King R, et al. (2009) Editorial: Introduction to the Supplement on HIV, HAART, and Fertility in sub-Saharan Africa. AIDS Behav 13 (Suppl 1): 1-4.

39. Mantell JE, Smit JA, Stein ZA (2009) The right to choose parenthood among HIV-infected women and men. J Public Health Policy 30: 367-378.

40. Myer L, Akugizibwe P (2009) Impact of HIV treatment scale-up on women's reproductive health care and reproductive rights in Southern Africa. J Acquir Immune Defic Syndr 52 (Suppl 1): S52-53.

41. Makumbi FE, Nakigozi G, Reynolds SJ, Ndyanabo A, Lutalo T, et al. (2011) Associations between HIV Antiretroviral Therapy and the Prevalence and Incidence of Pregnancy in Rakai, Uganda. AIDS Res Treat 2011: 519492.

42. Myer L, Carter RJ, Katyal M, Toro P, El-Sadr WM, et al. (2010) Impact of antiretroviral therapy on incidence of pregnancy among HIV-infected women in Sub-Saharan Africa: a cohort study. PLoS Med 7: e1000229.

43. Uganda Bureau of Statistics and Macro International Inc. (2007) Uganda Demographic and Health Survey 2006. Calverton: Uganda Bureau of Statistics and Macro International Inc.

44. World Health Organization (WHO) (2011) Global HIV/AIDS response: epidemic update and health sector progress towards universal access: Progress report 2011. Geneva: WHO.

45. Ministry of Health (Uganda) and ORC Macro (2006) Uganda HIV/AIDS Serobehavioural survey 2004-2005. Calverton, MD: Ministry of Health (Uganda) and ORC Macro.

46. Geng EH, Bwana MB, Kabakyenga J, Muyindike W, Emenyonu NI, et al. (2010) Diminishing availability of publicly funded slots for antiretroviral initiation among HIV-infected ART-eligible patients in Uganda. PLoS ONE 5: e14098.

47. Uganda Ministry of Health (2009) National Antiretroviral Treatment Guidelines for Adults, Adolescents, and Children, 3rd edition. Kampala: Uganda Ministry of Health.

48. Uganda Ministry of Health (2008) National Antiretroviral Treatment and Care Guidelines for Adults, Adolescents, and Children, 2nd edition. Kampala: Uganda Ministry of Health.

49. Uganda Ministry of Health (2003) National Antiretroviral Treatment and Care Guidelines for Adults and Children, 1st edition. Kampala: Uganda Ministry of Health.

50. Awiti Ujiji O, Ekstrom AM, Ilako F, Indalo D, Rubenson B (2010) "I will not let my HIV status stand in the way." Decisions on motherhood among women on ART in a slum in Kenya- a qualitative study. BMC Womens Health 10: 13.

51. Blair JM, Hanson DL, Jones JL, Dworkin MS (2004) Trends in pregnancy rates among women with human immunodeficiency virus. Obstet Gynecol 103: 663668.

52. Desgrees-Du-Lou A, Msellati P, Viho I, Yao A, Yapi D, et al. (2002) Contraceptive use, protected sexual intercourse and incidence of pregnancies among African HIV-infected women. DITRAME ANRS 049 Project, Abidjan 1995-2000. Int J STD AIDS 13: 462-468.

53. Guthrie BL, Choi RY, Bosire R, Kiarie JN, Mackelprang RD, et al. (2010) Predicting pregnancy in HIV-1-discordant couples. AIDS Behav 14: 1066-1071.

54. Sharma A, Feldman JG, Golub ET, Schmidt J, Silver S, et al. (2007) Live birth patterns among human immunodeficiency virus-infected women before and after the availability of highly active antiretroviral therapy. Am J Obstet Gynecol 196: 541 e 541-546.

55. Simbayi LC, Kalichman SC, Strebel A, Cloete A, Henda N, et al. (2007) Disclosure of HIV status to sex partners and sexual risk behaviours among HIVpositive men and women, Cape Town, South Africa. Sex Transm Infect 83: 29 34.

56. Bolton P, Ndogoni L (2001) Cross-cultural assessment of trauma-related mental illness (Phase II): A report of research conducted by World Vision Uganda and The Johns Hopkins University. US Agency for International Development, The Johns Hopkins University, and World Vision International.

57. Derogatis LR, Lipman RS, Rickels K, Uhlenhuth EH, Covi L (1974) The Hopkins Symptom Checklist (HSCL): a self-report symptom inventory. Behav Sci 19: 1-15.

58. Martinez P, Andia I, Emenyonu N, Hahn JA, Hauff E, et al. (2008) Alcohol use, depressive symptoms and the receipt of antiretroviral therapy in southwest Uganda. AIDS Behav 12: 605-612.

59. Revicki DA, Sorensen S, Wu AW (1998) Reliability and validity of physical and mental health summary scores from the Medical Outcomes Study HIV Health Survey. Med Care 36: 126-137.

60. Wu AW (1999) MOS-HIV Health Survey Users' Manual. Baltimore: Johns Hopkins Bloomberg School of Public Health

61. Lin DY, Wei LJ (1989) The robust inference for the Cox proportional hazards model. Journal of the American Statistical Association 84: 1074-1078.

62. Akaike H (1974) A new look at the statistical model identification. IEEE Transactions on Automatic Control 19: 716-723.

63. The SAS Institute (2011) SAS version 9.3. Cary: NC: The SAS Institute.

64. Bussmann H, Wester CW, Wester CN, Lekoko B, Okezie O, et al. (2007) Pregnancy rates and birth outcomes among women on efavirenz-containing highly active antiretroviral therapy in Botswana. J Acquir Immune Defic Syndr 45: 269-273.

65. Tweya H, Feldacker C, Breeze E, Jahn A, Haddad LB, et al. (2012) Incidence of pregnancy among women accessing Antiretroviral therapy in urban Malawi: A retrospective cohort study. AIDS Behav.

66. Gibb DM, Kizito H, Russell EC, Chidziva E, Zalwango E, et al. (2012) Pregnancy and infant outcomes among HIV-infected women taking long-term ART with and without tenofovir in the DART trial. PLoS Med 9: e1001217.

67. Schwartz SR, Mehta SH, Taha TE, Rees HV, Venter F, et al. (2012) High pregnancy intentions and missed opportunities for patient-provider communication about fertility in a South African cohort of HIV-positive women on antiretroviral therapy. AIDS Behav 16: 69-78.

68. Kabami J, Bajunirwe F (2011) Incidence and predictors of pregnancy among women receiving HIV care and treatment at a large urban facility in Western Uganda. $6^{\text {th }}$ International AIDS Society (IAS) conference on HIV Pathogenesis, Treatment and Prevention Rome, Italy.

69. Heffron R, Were E, Celum C, Mugo N, Ngure K, et al. (2010) A prospective study of contraceptive use among African women in HIV-1 serodiscordant partnerships. Sex Transm Dis 37: 621-628.

70. Taulo F, Berry M, Tsui A, Makanani B, Kafulafula G, et al. (2009) Fertility intentions of HIV-1 infected and uninfected women in Malawi: a longitudinal study. AIDS Behav 13 Suppl 1: 20-27.

71. Schwartz SR, Rees H, Mehta S, Venter WD, Taha TE, et al. (2012) High incidence of unplanned pregnancy after antiretroviral therapy initiation: findings from a prospective cohort study in South Africa. PLoS ONE 7: e36039.

72. US Census Bureau International Programs (2008) Global Population Profile (2008) International Data Base: Age-Specific Fertility Rates and Selected Derived Measures: US Census Bureau.

73. Lewis JJ, Ronsmans C, Ezeh A, Gregson S (2004) The population impact of HIV on fertility in sub-Saharan Africa. AIDS 18 (Suppl 2): S35-43. 
74. Linas BS, Minkoff H, Cohen MH, Karim R, Cohan D, et al. (2011) Relative time to pregnancy among HIV-infected and uninfected women in the Women's Interagency HIV Study, 2002-2009. AIDS 25: 707-711.

75. Zaba B, Gregson S (1998) Measuring the impact of HIV on fertility in Africa. AIDS 12 (Suppl 1): S41-50.

76. Snow RC, Mutumba M, Resnicow K, Mugyenyi G (2013) The social legacy of AIDS: Fertility aspirations among HIV-affected women in Uganda. Am J Public Health 103: 278-285.

77. Muyindike W, Fatch R, Steinfield R, Matthews LT, Musinguzi N, et al. (2012) Contraceptive Use and Associated Factors among Women Enrolling into HIV Care in Southwestern Uganda. Infect Dis Obstet Gynecol 2012: 340782.

78. Polis CB, Gray RH, Lutalo T, Nalugoda F, Kagaayi J, et al. (2011) Trends and correlates of hormonal contraceptive use among HIV-infected women in Rakai, Uganda, 1994-2006. Contraception 83: 549-555.

79. Agangi A, Thorne C, Newell ML (2005) Increasing likelihood of further live births in HIV-infected women in recent years. BJOG 112: 881-888.

80. van Benthem BH, de Vincenzi I, Delmas MC, Larsen C, van den Hoek A, et al. (2000) Pregnancies before and after HIV diagnosis in a european cohort of HIVinfected women. European Study on the Natural History of HIV Infection in Women. AIDS 14: 2171-2178.

81. Cooper D, Harries J, Myer L, Orner P, Bracken H, et al. (2007) "Life is still going on": reproductive intentions among HIV-positive women and men in South Africa. Soc Sci Med 65: 274-283.

82. Andia I, Kaida A, Maier M, Guzman D, Emenyonu N, et al. (2009) Highly active antiretroviral therapy and increased use of contraceptives among HIV- positive women during expanding access to antiretroviral therapy in Mbarara, Uganda. Am J Public Health 99: 340-347.

83. Matthews L, Crankshaw T, Giddy J, Kaida A, Psaros C, et al. (2012) Reproductive counseling by clinic healthcare workers in Durban, South Africa: perspectives from HIV-positive men and women reporting serodiscordant partners. Infectious Diseases in Obstetrics and Gynecology 2012: 9.

84. Myer L, Rebe K, Morroni C (2007) Missed opportunities to address reproductive health care needs among HIV-infected women in antiretroviral therapy programmes. Trop Med Int Health 12: 1484-1489.

85. DeCherney AH, Berkowitz GS (1982) Female fecundity and age. N Engl J Med 306: $424-426$

86. United Nations Population Division (2009) World Fertility Data 2008. Geneva.

87. Kisakye P, Akena WO, Kaye DK (2010) Pregnancy decisions among HIVpositive pregnant women in Mulago Hospital, Uganda. Cult Health Sex 12: $445-454$.

88. King R, Katuntu D, Lifshay J, Packel L, Batamwita R, et al. (2008) Processes and outcomes of HIV serostatus disclosure to sexual partners among people living with HIV in Uganda. AIDS Behav 12: 232-243.

89. Kastner J, Erikson S, Matthews LT, Berry N, Ninsiima F, et al. (2013) Tracing multi-level factors that influence pregnancy desires of HIV-positive women on ART in south-western Uganda (Abstract no. 31). Afri-Can Forum. Entebbe, Uganda (January 17-19, 2013).

90. King R, Khana K, Nakayiwa S, Katuntu D, Homsy J, et al. (2011) 'Pregnancy comes accidentally-like it did with me': reproductive decisions among women on ART and their partners in rural Uganda. BMC Public Health 11: 530. 